\title{
Abdominal pain due to the spinothalamic tract injury in patients with mild traumatic brain injury: a case report
}

\author{
Sung Ho Jang, Young Hyeon Kwon and Sung Jun Lee*
}

\begin{abstract}
Background: We report on a patient with a mild traumatic brain injury (TBI) who developed abdominal pain due to spinothalamic tract (STT) injuries revealed by diffusion tensor tractography (DTT).

Case presentation: A 53-year-old female patient suffered head trauma resulting from a backward fall. While bathing at a public bathhouse, she fell backward and struck the occipital area of her head against the floor. After the head trauma, she experienced pain in the abdomen and in both hands and feet. She underwent evaluations including conventional brain MRI, abdominal and pelvic ultrasonography, and stomach and intestine endoscopy. No abnormality was observed in her brain or abdomen. In addition, her abdominal pain had not been relieved by medical management. When she came to our hospital 4 years after the head trauma, her pain characteristics and severity were as follows: intermittent pain without allodynia or hyperalgesia; squeezing and warm creeping-like pain in the abdomen (visual analog scale score: 7); tingling pain in both hands and feet (visual analog scale score: 7). She was prescribed pregabalin and gabapentin, and her abdominal and limb pain was well-controlled at a tolerable level. On DTT 4 years after head trauma, the upper portion of the spinothalamic tracts (STS) in both hemispheres showed partial tearing.

Discussion and conclusions: Injury of the STT was demonstrated by using DTT in a patient who showed abdominal pain that was refractory to medical management following mild TBI. Our results suggest that central pain due to STT injury might be suspected in patients with abdominal pain that is refractory to medical management following TBI.
\end{abstract}

Keywords: Diffusion tensor tractography, Spinothalamic tract, Traumatic axonal injury, Head trauma, Brain injury

\section{Background}

Central pain with characteristics of neuropathic pain is caused by injury of the central nervous system [1]. It has been reported that approximately $69 \%$ of patients with mild traumatic brain injury (TBI) experience central pain due to injury of the spinothalamic tract (STT) [2]. Because the management strategy for and the prognosis of central pain differ significantly from those for other

\footnotetext{
* Correspondence: hssj8020@hanmail.net

Department of Physical Medicine and Rehabilitation, College of Medicine, Yeungnam University 317-1, Daemyungdong, Namku, Taegu 705-717, Republic of Korea
}

pains ascribed to other pathophysiological etiologies, the elucidation of the pathophysiology of central pain is clinically important for patients with TBI [2].

The recent development of diffusion tensor tractography (DTT), images of which are reconstructed from diffusion tensor imaging (DTI) data, allows three-dimensional visualization and estimation of the STT [3]. Many studies using DTT have reported that injury of the STT is related to the pathophysiology of central pain in mild TBI [2-9]. Most of these studies have reported on central pain of the arm and leg. Conversely, no study on abdominal pain due to the STT injury has been reported.

(c) The Author(s). 2020 Open Access This article is licensed under a Creative Commons Attribution 4.0 International License, which permits use, sharing, adaptation, distribution and reproduction in any medium or format, as long as you give appropriate credit to the original author(s) and the source, provide a link to the Creative Commons licence, and indicate if changes were made. The images or other third party material in this article are included in the article's Creative Commons licence, unless indicated otherwise in a credit line to the material. If material is not included in the article's Creative Commons licence and your intended use is not permitted by statutory regulation or exceeds the permitted use, you will need to obtain permission directly from the copyright holder. To view a copy of this licence, visit http://creativecommons.org/licenses/by/4.0/ The Creative Commons Public Domain Dedication waiver (http://creativecommons.org/publicdomain/zero/1.0/) applies to the data made available in this article, unless otherwise stated in a credit line to the data. 
In the current study, we report on a patient with mild TBI who developed abdominal pain. Results of DTT revealed that the patient had an injury of the STT.

\section{Case presentation}

A 53-year-old female patient suffered a head trauma from a backward fall. While bathing at a public bathhouse, she fell backward and struck the occipital area of her head against the floor. The patient mentioned that she experienced loss of consciousness and post-traumatic amnesia for approximately $30 \mathrm{~min}$ after the accident. Her Glasgow Coma Scale was 15 when she arrived at the hospital $[3,10]$. After the head trauma, she experienced pain in the abdomen and in both hands and feet as well as memory impairment, dysarthria, depressive mood, and auditory impairment which are common symptoms of TBI. She visited several hospitals and underwent various evaluations including conventional brain magnetic resonance imaging (MRI), abdominal and pelvic ultrasonography, and stomach and intestine endoscopy. No abnormalities were observed in her brain, abdomen, and pelvic organ. In addition, her abdominal pain had not been relieved by any medical management mainly at the department of internal medicine. Four years after the head trauma, she came to the rehabilitation department of our university hospital for evaluation of her brain. No specific lesion was observed on brain MRI that included T1weighted, T2-weighted, and fluid-attenuated inversion recovery [FLAIR] images (Fig. 1a). Electromyography, nerve conduction and motor evoked potential studies for both upper and lower extremities, and paraspinal muscles did not show any abnormality. The characteristics and severity of her pain were assessed as follows: intermittent pain without allodynia or hyperalgesia; squeezing and warm creeping-like pain in the abdomen (visual analog scale

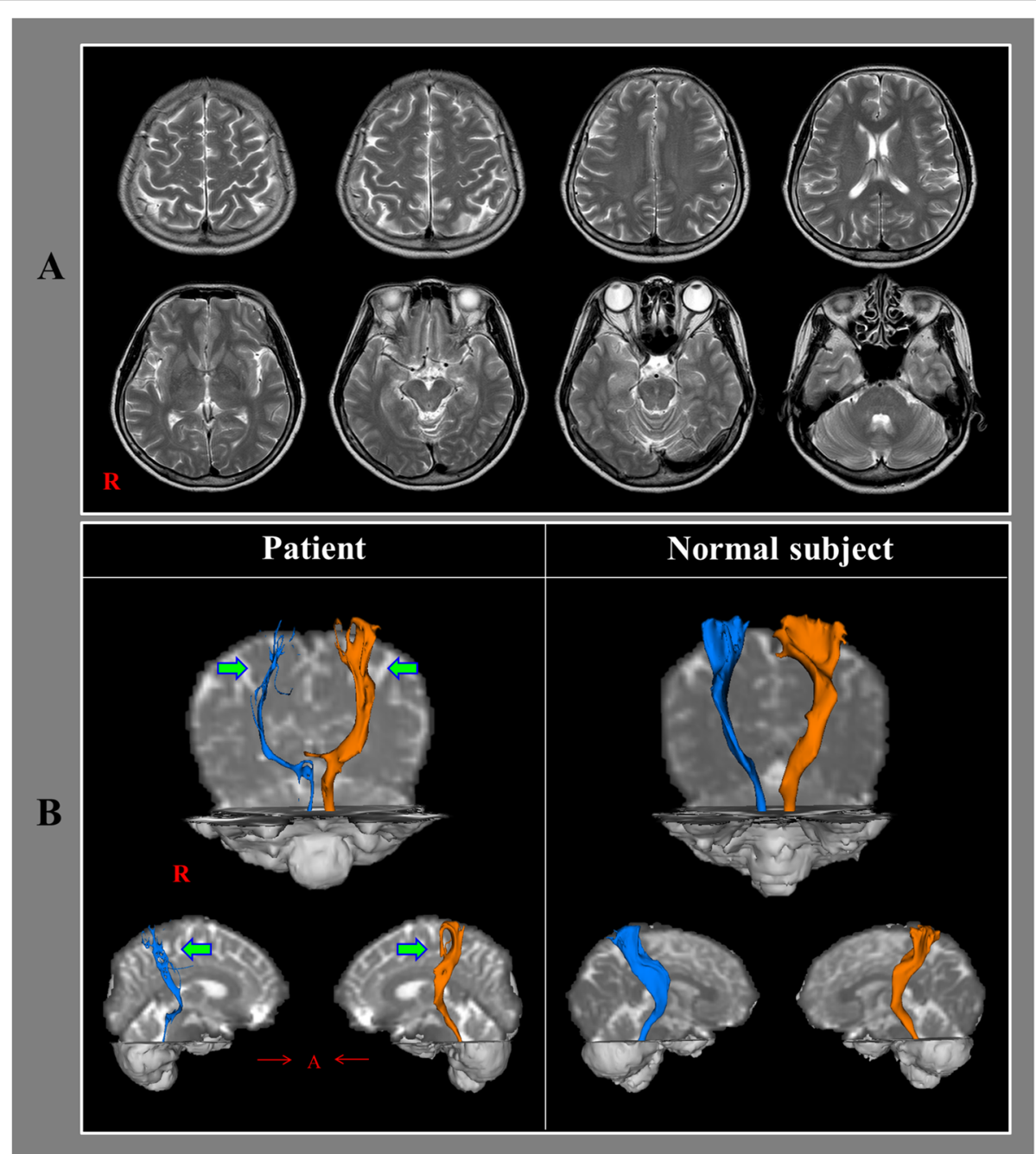

Fig. 1 a T2-weighted brain magnetic resonance images taken at 4 years after onset shows no definite lesion. b Results of four-year post-trauma diffusion tensor tractography. In both hemispheres, the spinothalamic tract (STT) shows partial tearing in the upper portion (arrows) compared with those in a normal control (51-year-old female) 
score: 7); tingling pain in both hands and feet (visual analog scale score: 7). She notified that her pain was a little decreased with the passage of time from onset [11]. She was prescribed pregabalin $(150 \mathrm{mg} /$ day) and gabapentin (300 $\mathrm{mg} /$ day), and her abdominal and limb pain was wellcontrolled at a tolerable level. The patient provided signed, informed consent, and our institutional review board approved the study protocol.

\section{Diffusion tensor Tractography}

DTI data were acquired 4 years after the patient's head trauma by using a six-channel head coil on a $1.5 \mathrm{~T}$ Philips Gyroscan Intera (Philips, Best, Netherlands). For each of the 32 non-collinear diffusion sensitizing gradients, 70 contiguous slices were acquired parallel to the anterior commissure-posterior commissure line. Imaging parameters were as follows: acquisition matrix $=96 \times 96$; reconstructed matrix $=192 \times 192$; field of view $=240 \times$ $240 \mathrm{~mm}^{2} ; \mathrm{TR}=10,726 \mathrm{~ms} ; \mathrm{TE}=76 \mathrm{~ms}$; parallel imaging reduction factor (SENSE factor) $=2$; EPI factor $=49 ; \mathrm{b}=$ $1000 \mathrm{~s} / \mathrm{mm}^{2} ; \mathrm{NEX}=1$; and slice thickness $=2.5 \mathrm{~mm}$ with no gap. For assessment of the STT, the Oxford Centre for Functional Magnetic Resonance Imaging of the Brain (FMRIB) Software Library (www.fmrib.ox.ac.uk/fsl) was used for analysis of DTI data. Affine multi-scale twodimensional registration was used for correction of head motion effects and image distortion due to eddy currents. Fiber tracking was performed by using a probabilistic tractography method based on a multi-fiber model and was applied in the current study by utilizing tractography routines implemented in FMRIB Diffusion software $(5000$ streamline samples, $0.5 \mathrm{~mm}$ step lengths, curvature thresholds $=0.2$ ). The STT was reconstructed by selecting fibers passing through regions of interest (ROI). To assess the STT, the seed ROI was placed in the posterolateral medulla on an axial slice, and two target ROIs with the option of termination were placed on a portion of the ventro-postero-lateral nucleus of the thalamus and primary somatosensory cortex [3]. The threshold values of two streamlines were applied for the results of fiber tracking for each tract.

On four-year post-trauma DTT, the upper portion of the STT in both hemispheres showed partial tearing (Fig. 1b).

\section{Discussion and conclusions}

In this study, the patient experienced abdominal and limb pain after a head trauma. However, the precise cause of her pain had not been determined even though she had visited several hospitals and underwent various evaluations of her brain and abdomen. Partial STT injuries (i.e., partial tearing) in both hemispheres were observed on four-year DTT. Her abdominal and limb pain were wellcontrolled by administration of specific drugs (pregabalin and gabapentin) for neuropathic pain, which was not relieved by medical management [12]. As a result, her pain appeared to be related to the STT injury. No definite brain lesion was detected on conventional brain MRI, but injury of both STTs in the brain appeared to be the cause of the central pain; thus, traumatic axonal injury was the most likely pathogenetic mechanism for the STT injuries [10, 13-15].

In summary, by using DTT, STT injury was demonstrated in a patient who showed abdominal pain that was refractory to any medical management following mild TBI. Our results suggest that central pain from STT injury might be suspected in patients with abdominal pain that is not relieved by medical management following TBI. As a result, evaluation of the STT using DTT would be useful in patients who reveal unexplained and refractory abdominal pain following TBI. However, because this is a case report, the results have limited generalizability. Therefore, further studies that include larger numbers of cases are warranted. In addition, the limitations of DTT should be considered because regions of fiber complexity and fiber crossing can prevent full reflection of the underlying fiber architecture by DTT; thus, DTT may underestimate the fibers of the neural tracts [16].

\section{Abbreviations \\ TBI: Traumatic brain injury; STT: Spinothalamic tract; DTT: Diffusion tensor tractography; DTI: Diffusion tensor imaging; MRI: Magnetic resonance imaging; FMRIB: Functional Magnetic Resonance Imaging of the Brain; ROI: Regions of interest}

\section{Acknowledgements}

Not applicable.

\section{Authors' contributions}

SHJ, study concept and design, manuscript development, writing, and funding. YHK, study concept, drafting/revising the image. SJL, writing, critical revision of manuscript for intellectual content, drafting/revising the image. All authors approved the contents of this case report.

\section{Funding}

Analysis and interpretation of data in writing the manuscript was supported by the Medical Research Center Program (2015R1A5A2009124) through the National Research Foundation of Korea (NRF) funded by the Ministry of Science, ICT and Future Planning.

\section{Availability of data and materials}

The datasets used and/or analysed during the current case reports are available from the corresponding author on reasonable request.

Ethics approval and consent to participate

The patient provided signed, informed consent, and our institutional review board approved the study protocol.

Consent for publication

Written consent for publication was obtained from the patient.

Competing interests

The authors declare that they have no competing interests. 
Received: 24 September 2019 Accepted: 24 March 2020

Published online: 02 April 2020

\section{References}

1. Klit H, Finnerup NB, Jensen TS. Central post-stroke pain: clinical characteristics, pathophysiology, and management. Lancet Neurol. 2009;8: 857-68.

2. Kim JH, Ahn SH, Cho YW, Kim SH, Jang SH. The relation between injury of the spinothalamocortical tract and central pain in chronic patients with mild traumatic brain injury. J Head Trauma Rehabil. 2015;30:E40-E6.

3. Hong JH, Son SM, Jang SH. Identification of spinothalamic tract and its related thalamocortical fibers in human brain. Neurosci Lett. 2010;468:102-5.

4. Hong JH, Kwon HG, Jang SH. Probabilistic somatotopy of the spinothalamic pathway at the ventroposterolateral nucleus of the thalamus in the human brain. AJNR Am J Neuroradiol. 2011:32:1358-62.

5. Seo JP, Jang SH. Injury of the spinothalamic tract in a patient with mild traumatic brain injury: diffusion tensor tractography study. J Rehabil Med. 2014;46:374-7.

6. Jang $\mathrm{SH}$, Kwon HG. Degeneration of an injured spinothalamic tract in a patient with mild traumatic brain injury. Brain Inj. 2016;30:1026-8.

7. Jang $\mathrm{SH}$, Lee HD. Central pain due to spinothalamic tract injury caused by indirect head trauma following a pratfall. Brain Inj. 2016;30:933-6.

8. Jang SH, Seo YS. Central pain due to spinothalamic tract injury by head trauma caused by falling object. Ann Rehabil Med. 2016;40:1149-50

9. Jang $\mathrm{SH}$, Lee HD. Severe and extensive traumatic axonal injury following minor and indirect head trauma. Brain Inj. 2017;31:416-9.

10. Alexander MP. Mild traumatic brain injury: pathophysiology, natural history, and clinical management. Neurology. 1995:45:1253-60.

11. Miller MD, Ferris DG. Measurement of subjective phenomena in primary care research: the visual analogue scale. Fam Pract Res J. 1993:13:15-24.

12. Dosenovic S, Jelicic Kadic A, Miljanovic M, et al. Interventions for neuropathic pain: an overview of systematic reviews. Anesth Analg. 2017; 125:643-52.

13. Povlishock JT, Christman CW. The pathobiology of traumatically induced axonal injury in animals and humans: a review of current thoughts. J Neurotrauma. 1995;12:555-64.

14. Shenton ME, Hamoda HM, Schneiderman JS, et al. A review of magnetic resonance imaging and diffusion tensor imaging findings in mild traumatic brain injury. Brain Imaging Behav. 2012;6:137-92.

15. Jang SH. Traumatic axonal injury in mild traumatic brain injury. In: Gorbunoy N, editor. Traumatic brain injury. London: InTech; 2018. p. 137-54.

16. Parker GJ, Alexander DC. Probabilistic anatomical connectivity derived from the microscopic persistent angular structure of cerebral tissue. Philos Trans R Soc Lond Ser B Biol Sci. 2005:360:893-902.

\section{Publisher's Note}

Springer Nature remains neutral with regard to jurisdictional claims in published maps and institutional affiliations.

Ready to submit your research? Choose BMC and benefit from:

- fast, convenient online submission

- thorough peer review by experienced researchers in your field

- rapid publication on acceptance

- support for research data, including large and complex data types

- gold Open Access which fosters wider collaboration and increased citations

- maximum visibility for your research: over $100 \mathrm{M}$ website views per year

At BMC, research is always in progress.

Learn more biomedcentral.com/submissions 